Case Report

\title{
Acute Liver Failure Occurring during the First Trimester of Pregnancy Successfully Treated with Living Donor Liver Transplantation
}

\author{
Naoya Kanogawa, ${ }^{1}$ Tatsuo Kanda, ${ }^{1}$ Masayuki Ohtsuka, ${ }^{2}$ Masato Nakamura, \\ Tatsuo Miyamura, ${ }^{1}$ Shin Yasui, ${ }^{1}$ Makoto Arai, ${ }^{1}$ Hitoshi Maruyama, ${ }^{1}$ Keiichi Fujiwara, \\ Makio Shozu, ${ }^{3}$ Shigeto Oda, ${ }^{4}$ Masaru Miyazaki, ${ }^{2}$ and Osamu Yokosuka ${ }^{1}$ \\ ${ }^{1}$ Department of Gastroenterology and Nephrology, Chiba University, Graduate School of Medicine, \\ 1-8-1 Inohana, Chuo-ku, Chiba 260-8677, Japan \\ ${ }^{2}$ Department of General Surgery, Chiba University, Graduate School of Medicine, Chuo-ku, Chiba 260-8677, Japan \\ ${ }^{3}$ Department of Reproductive Medicine, Chiba University, Graduate School of Medicine, Chuo-ku, Chiba 260-8677, Japan \\ ${ }^{4}$ Department of Emergency and Critical Care Medicine, Chiba University, Graduate School of Medicine, \\ Chuo-ku, Chiba 260-8677, Japan \\ Correspondence should be addressed to Tatsuo Kanda; kandat-cib@umin.ac.jp
}

Received 1 October 2013; Accepted 13 November 2013

Academic Editors: D. Capone, C. F. Classen, C. Costa, and F. Keller

Copyright (C) 2013 Naoya Kanogawa et al. This is an open access article distributed under the Creative Commons Attribution License, which permits unrestricted use, distribution, and reproduction in any medium, provided the original work is properly cited.

Acute liver failure (ALF) during pregnancy remains difficult to treat, and despite advances in treatment, liver transplantation must be selected as treatment option in certain cases. We report a 30-year-old woman with ALF of unknown etiology, occurring during the first trimester of pregnancy. Her condition was complicated by consciousness disturbance and coagulopathy due to ALF, but she was successfully treated with living donor liver transplantation 7 days after dilatation and curettage. At 9-month followup, she was in good medical condition. Liver transplantation has been reported as one of the treatment options for ALF during pregnancy with the prognosis varying depending on the trimester, from living donor or deceased donor liver transplantation. Of importance is that clinicians always think of emergent liver transplantation as a therapeutic option in ALF even in the first trimester of pregnancy.

\section{Introduction}

Liver disease during pregnancy is classified into three categories as follows: (1) specific to pregnancy, (2) coincidental with pregnancy, and (3) preexisting liver disease $[1,2]$. In the first trimester of a normal pregnancy, hyperemesis gravidarum occurs in 1-20 per 1000 pregnancies $[3,4]$. On the other hand, fatty liver of pregnancy, preeclampsia or eclampsia, and HELLP (haemolysis, elevated liver enzymes, and low platelets) syndrome are three representative pregnancyrelated diseases whose onset is usually between the 34th and the 36th weeks [1].

Treatment decisions for acute liver failure (ALF) are complicated by the diversity of its clinical presentations especially in pregnant women. Although liver transplantation supersedes empirical drug therapy in decompensated patients, pregnant patients warrant treatment modifications, and it is difficult to plan their therapies in certain cases because the lives of mother and baby should be rescued.

Although there have been several reports about liver transplantation from deceased donors for ALF occurring during pregnancy [5-26], it is relatively rare in the first trimester of pregnancy $[13,15]$. We experienced a case of acute liver failure, successfully treated with liver transplantation from a living related donor, which we report here.

\section{Case Report}

A 30-year-old woman at week 12 of pregnancy was referred and transferred to Chiba University School of Medicine 


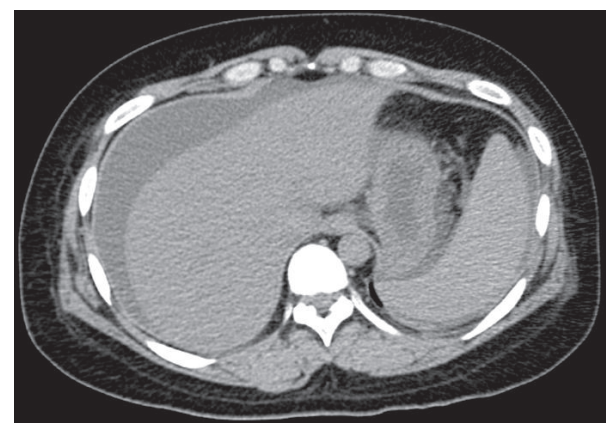

FIGURE 1: Computed tomography on admission showed atrophic liver and mild splenomegaly. There was moderate ascites but no evidence of cirrhosis.

Hospital from another hospital with 10 days of liver test abnormalities and jaundice, for consciousness disturbance and coagulopathy. On the first admission into another hospital, two days after her first symptom of jaundice, her laboratory findings were total bilirubin, $15.6 \mathrm{mg} / \mathrm{dL}$; AST, $2286 \mathrm{IU} / \mathrm{L}$; ALT, $1818 \mathrm{IU} / \mathrm{L}$; and prothrombin time, 37\%. She had been healthy, apart from suffering from a left wrist fracture three years earlier and occasionally taking loxoprofen for lower back pain. There was no history of liver disease, alcohol consumption, or transfusion. She had 5 children, who were born via normal vaginal delivery, and she did not show liver test abnormalities at the time of their births. Her family had no history of liver disease. On physical examination, she was obese (her weight, $95 \mathrm{~kg}$; body length, $1.70 \mathrm{~m}$; and body mass index, $32.5 \mathrm{~kg} / \mathrm{m}^{2}$ ) and found to be deeply jaundiced. Flapping tremor, disorientation, and hepatic encephalopathy grade III were noted. On admission to our hospital, her laboratory findings had deteriorated as follows: total bilirubin, $20.5 \mathrm{mg} / \mathrm{dL}$; AST, $281 \mathrm{IU} / \mathrm{L}$; ALT, $495 \mathrm{IU} / \mathrm{L}$; prothrombin time, $12 \%$; international normalized ratio (INR), $3.25 ; \mathrm{NH}_{3}, 131 \mu \mathrm{g} / \mathrm{dL}$; AFP, $10 \mathrm{ng} / \mathrm{mL}$; and hepatocyte growth factor, $4.43 \mathrm{ng} / \mathrm{mL}$ (normal $<0.4 \mathrm{ng} / \mathrm{mL}$ ). Serum IgG, IgM, ceruloplasmin and copper were at normal levels, but IgA $(418 \mathrm{mg} / \mathrm{dL})$ and urine copper $(471.6 \mu \mathrm{g} /$ day $)$ were slightly elevated. Viral serology was negative for $\mathrm{HBsAg}$, anti-HBc IgM, anti-HAV IgM, anti-HCV, anti-HEV IgA, anti-HSV IgM, anti-VZV IgM, anti-EBV VCA, and anti-HIV. Serum HBV DNA, HCV RNA, and HEV RNA were all negative. Anti-CMV IgM was weakly positive but CMV-antigen was negative. Serum antinuclear antibody was slightly positive, but antimitochondrial and antismooth muscle antibodies were negative. Abdominal ultrasound and computed tomography (CT) demonstrated moderate ascites, atrophic liver, and slight splenomegaly but no collateral vessels (Figure 1). On admission, MELD score was 31. We started to perform online hemodiafiltration concomitant with slow plasma exchange twice as artificial liver supports, and performed dilatation and curettage one day after admission to improve consciousness disturbance and coagulopathy. Seven days later, as her general hepatic status and MELD score did not improve, urgent transplant of a liver from a living related donor, her healthy father, was performed. The patient was

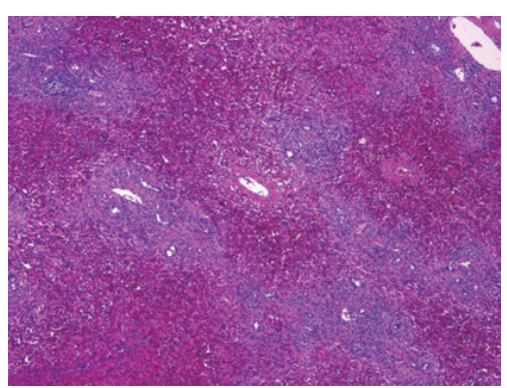

(a)

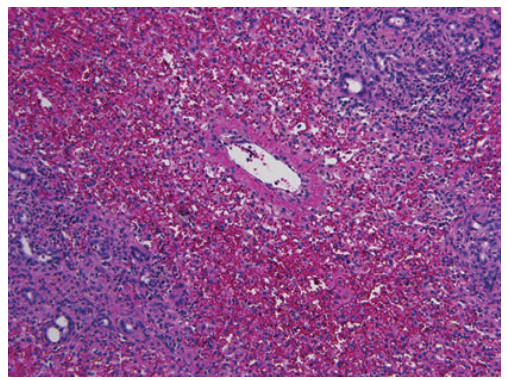

(b)

FIGURE 2: The recipient's explanted liver showed no cirrhosis, and the hepatic architecture was preserved (hematoxylin and eosin; original magnification 40x) (a). Massive hemorrhagic hepatic necrosis was also seen (hematoxylin and eosin; original magnification 200x) (b).

discharged with nearly normal liver function at 3 months after surgery, and she and her father were at home in good health at 9 months.

The explanted liver weighed $720 \mathrm{~g}$; there was no sign of cirrhosis, and the hepatic architecture was preserved (Figure 2(a)). Liver histology of the affected liver was consistent with massive necrosis and extensive coagulative necrosis (Figure 2(b)).

\section{Discussion}

Severe hepatic injury and hepatotoxicity including ALF are also occasionally seen in the first trimester of pregnancy [2], although representative pregnancy-related diseases, such as pregnancy-related fatty liver diseases, often causing ALF, occur more often in the late stage of pregnancy [1]. The present case occurred during the first trimester of pregnancy. After dilatation and curettage, the patient's liver function did not improve and living donor liver transplantation from her father was performed for her rescue.

There have been several reports about liver transplantation for ALF, occurring during pregnancy, either from deceased donors [5-15] or living donors [16-20]. The causes of ALF during pregnancy requiring liver transplantation were various as follows: hepatitis viral infection $[6,8,14,20,21]$, drug-associated [5, 21, 24, 25], autoimmune hepatitis [10], acute fatty liver of pregnancy (AFLP) [11, 22], and unknown etiology $[7,9,12,13,15-19,26]$. Thus, the majority of causes of ALF during pregnancy requiring liver transplantation are 
reported to be unknown, as was the cause of the present case, although drug-associated hepatitis induced by loxoprofen could not be completely ruled out. We did not expect our case as AFLP, which is one of the diseases of late pregnancy [1].

Gestational age of expectant mothers with ALF requiring liver transplantation was also related to various etiologies for their ALF. Only three cases of ALF with unknown etiology, including the present case, and occurring during the first trimester of pregnancy, required liver transplantation $[13,15]$.

Horikoshi et al. [19] reported that successful living donor liver transplantation for ALF of unknown etiology with onset immediately after cesarean delivery was performed at 33 weeks and 3 days of gestation and that this patient and her baby were in good medical condition. Living donor liver transplantation for ALF during the earlier trimester of pregnancy looked to relieve not the mother but her baby [17, $18,20]$. In the present case, living donor liver transplantation was also performed 7 days after her dilatation and curettage. In some cases of deceased donor liver transplantation, both mother and baby were alive $[13,15]$. Further studies about the differences between living donor and deceased donor transplantation will be needed.

In conclusion, liver transplantation for ALF during pregnancy was not rare and living donor related transplantation should be available on demand. Even if the ALF patient was in the first trimester of pregnancy, we should consider liver transplantation as a treatment option.

\section{References}

[1] A. K. Burroughs and E. J. Heathcote, "The liver in pregnancy," in Sherlock's Diseases of the Liver and Biliary System, J. S. Dooly, A. S. F. Lok, A. K. Burroughs, and E. J. Heathcoate, Eds., pp. 602614, John Wiley \& Sons, West Sussex, UK, 12th edition, 2011.

[2] T. Miyamura, T. Kanda, S. Minemura et al., "Acute liver failure associated with propylthiouracil in a pregnant 26-year-old woman," Case Reports in Gastroenterology, vol. 7, no. 2, pp. 240244, 2013.

[3] N. K. Kuşcu and F. Koyuncu, "Hyperemesis gravidarum: current concepts and management," Postgraduate Medical Journal, vol. 78, no. 916, pp. 76-79, 2002.

[4] D. B. Fell, L. Dodds, K. S. Joseph, V. M. Allen, and B. Butler, "Risk factors for hyperemesis gravidarum requiring hospital admission during pregnancy," Obstetrics and Gynecology, vol. 107, no. 2, part 1, pp. 277-284, 2006.

[5] C. V. Morris, R. M. Goldstein, J. B. Cofer, H. Solomon, and G. B. Klintmalm, "An unusual presentation of fulminant hepatic failure secondary to propylthiouracil therapy," Clinical transplants, p. 311, 1989.

[6] J. Fair, A. S. Klein, T. Feng, W. T. Merritt, and J. F. Burdick, "Intrapartum orthotopic liver transplantation with successful outcome of pregnancy," Transplantation, vol. 50, no. 3, pp. 534$535,1990$.

[7] E. G. Moreno, G. I. Garcia, S. R. Gomez et al., "Fulminant hepatic failure during pregnancy successfully treated by orthotopic liver transplantation," Transplantation, vol. 52, no. 5, pp. 923926, 1991.

[8] M. I. R. Hamilton, R. Alcock, L. Magos, S. Mallett, K. Rolles, and A. K. Burroughs, "Liver transplantation during pregnancy," Transplantation Proceedings, vol. 25, no. 5, pp. 2967-2968, 1993.
[9] D. E. Finlay, M. C. Foshager, D. G. Longley, and J. G. Letourneau, "Ischemic injury to the fetus after maternal liver transplantation," Journal of Ultrasound in Medicine, vol. 13, no. 2, pp. 145148, 1994.

[10] S. M. Catnach, M. McCarthy, E. Jauniaux et al., "Liver transplantation during pregnancy complicated by cytomegalovirus infection," Transplantation, vol. 60, no. 5, pp. 510-511, 1995.

[11] P. Remiszewski, J. Pawlak, A. Skwarek et al., "Orthotopic liver transplantation for acute liver failure resulting from 'acute fatty liver of pregnancy"' Annals of Transplantation, vol. 8, no. 3, pp. 8-11, 2003.

[12] N. Jarufe, A. Soza, R. M. Pérez-Ayuso et al., "Successful liver transplantation and delivery in a woman with fulminant hepatic failure occurring during the second trimester of pregnancy," Liver International, vol. 26, no. 4, pp. 494-497, 2006.

[13] Z. Jankovic, D. Stamenkovic, B. Duncan, R. Prasad, and M. Davies, "Successful outcome after a technically challenging liver transplant during pregnancy," Transplantation Proceedings, vol. 39, no. 5, pp. 1704-1706, 2007.

[14] L. Toti, T. M. Manzia, P. Romano et al., "Successful management of a same-day emergency delivery and liver transplant in a 27 weeks pregnant woman with fulminant hepatic failure," Transplant International, vol. 23, no. 1, pp. 114-115, 2010.

[15] V. C. Muddukuri, C. D. Stephenson, L. Eskind, W. A. Ahrens, P. Purdum, and M. W. Russo, "Liver transplantation for acute liver failure at 11-week gestation with successful maternal and fetal outcome," Case Reports in Transplantation, vol. 2012, Article ID 484080, 7 pages, 2012.

[16] C. M. Lo, P. Gertsch, and S. T. Fan, "Living unrelated liver transplantation between spouses for fulminant hepatic failure," British Journal of Surgery, vol. 82, no. 8, p. 1037, 1995.

[17] T. Kato, J. R. Nery, J. J. Morcos et al., "Successful living related liver transplantation in an adult with fulminant hepatic failure," Transplantation, vol. 64, no. 3, pp. 415-417, 1997.

[18] S. Eguchi, K. Yanaga, F. Fujita et al., "Living-related right lobe liver transplantation for a patient with fulminant hepatic failure during the second trimester of pregnancy: report of a case," Transplantation, vol. 73, no. 12, pp. 1970-1971, 2002.

[19] Y. Horikoshi, H. Itoh, S. Kikuchi et al., "Successful living donor liver transplantation for fulminant hepatic failure that manifested immediately after cesarean delivery," ASAIO Journal, vol. 58, no. 2, pp. 174-176, 2012.

[20] Y. Simsek, B. Isik, A. Karaer et al., "Fulminant hepatitis A infection in second trimester of pregnancy requiring living-donor liver transplantation," Journal of Obstetrics and Gynaecology, vol. 38, no. 4, pp. 745-748, 2012.

[21] S. A. Laifer, M. J. Darby, V. P. Scantlebury, J. H. Harger, and S. N. Caritis, "Pregnancy and liver transplantation," Obstetrics and Gynecology, vol. 76, no. 6, pp. 1083-1088, 1990.

[22] S. A. Ockner, E. M. Brunt, S. M. Cohn, E. S. Krul, D. W. Hanto, and M. G. Peters, "Fulminant hepatic failure caused by acute fatty liver of pregnancy treated by orthotopic liver transplantation," Hepatology, vol. 11, no. 1, pp. 59-64, 1990.

[23] M. Bourliere, Y. P. Le Treut, J. C. Manelli et al., "Chlormezanoneinduced fulminant hepatitis in a pregnant woman: successful delivery and liver transplantation," Journal of Gastroenterology and Hepatology, vol. 7, no. 3, pp. 339-341, 1992.

[24] E. J. Gill, M. J. Contos, and T. C. C. Peng, "Acute fatty liver of pregnancy and acetaminophen toxicity leading to liver failure and postpartum liver transplantation: A case report," Journal of Reproductive Medicine for the Obstetrician and Gynecologist, vol. 47, no. 7, pp. 584-586, 2002. 
[25] E. Sequeira, S. Wanyonyi, and R. Dodia, "Severe propylthiouracil-induced hepatotoxicity in pregnancy managed successfully by liver transplantation: a case report," Journal of Medical Case Reports, vol. 5, article 461, 2011.

[26] M. Anders, E. Quiñonez, N. Goldaracena et al., "Liver transplantation during pregnancy in a patient with acute liver failure," Acta Gastroenterologica Latinoamericana, vol. 40, no. 3, pp. 268-270, 2010. 


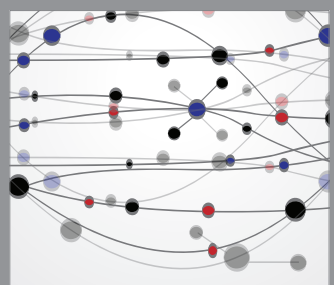

The Scientific World Journal
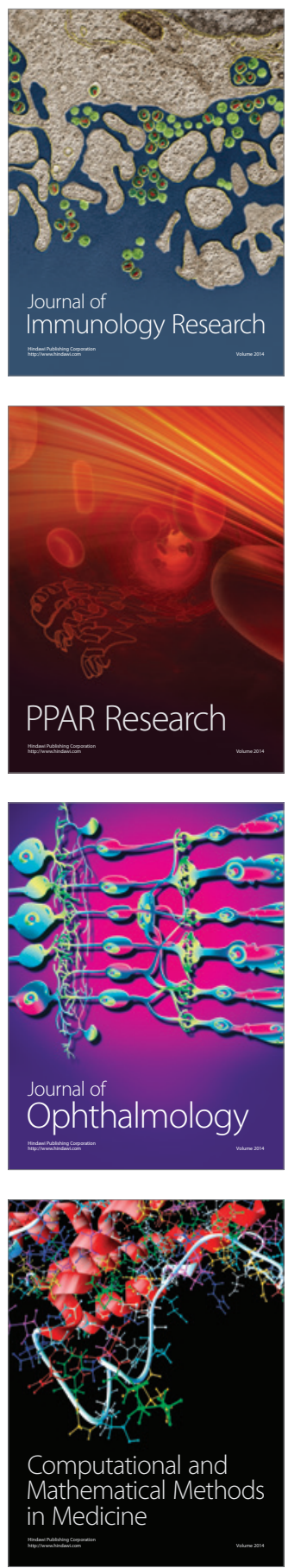

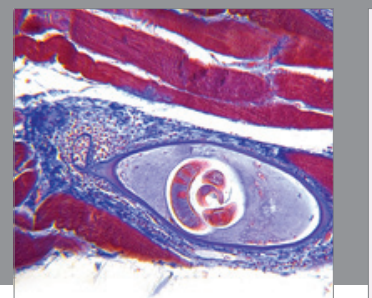

Gastroenterology

Research and Practice
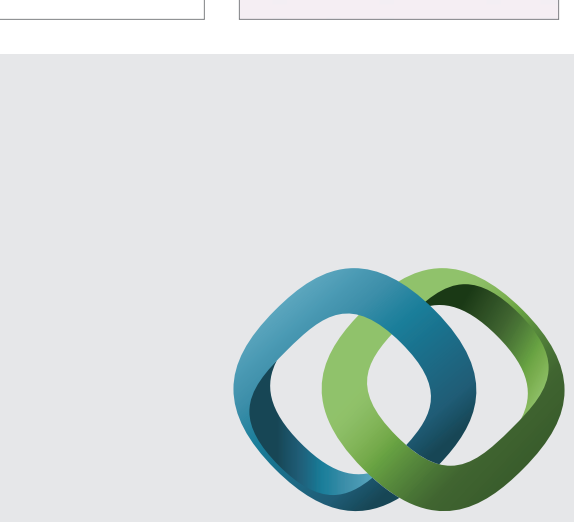

\section{Hindawi}

Submit your manuscripts at

http://www.hindawi.com
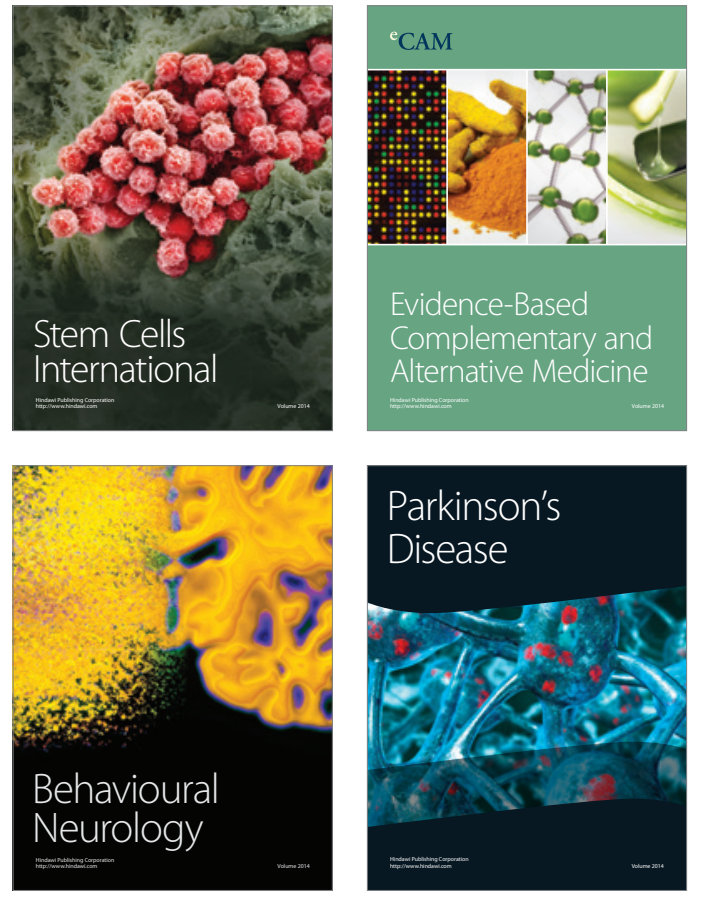
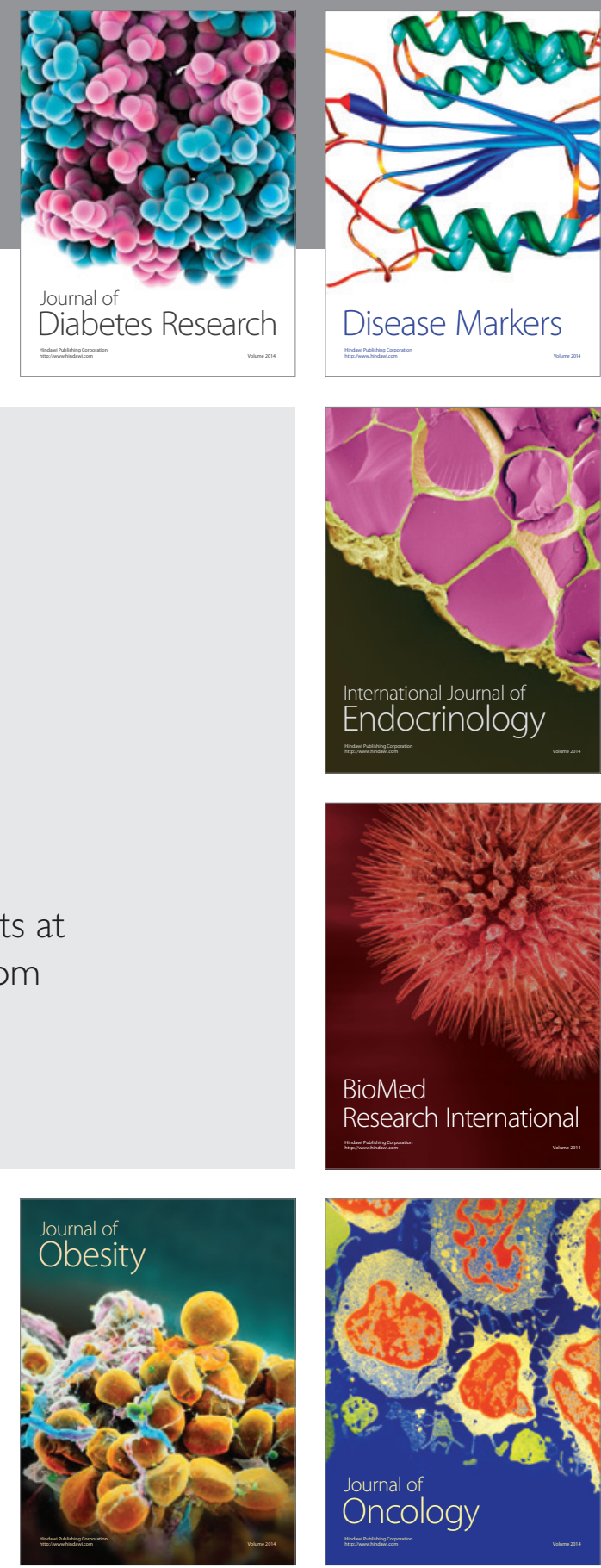

Disease Markers
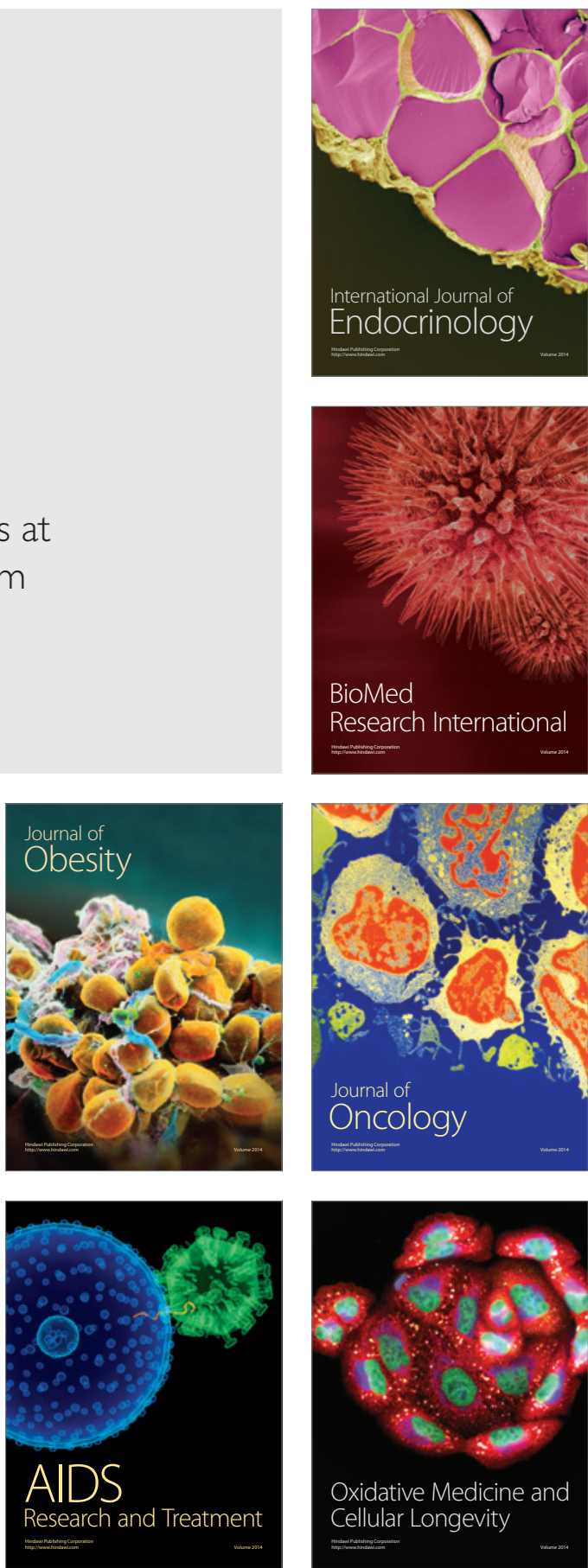